\title{
Assessment of Quality of Care Using Information on Patient Satisfaction at Adult Oncology Center of Tikur Anbessa Specialized Hospital, Ethiopia: A Cross-Sectional Study
}

This article was published in the following Dove Press journal:

Patient Preference and Adherence

\author{
Dessale Abate \\ Munir Awol Aman (D) ${ }^{2}$ \\ Beshir Bedru Nasir ${ }^{1}$ \\ Girma Tekle Gebremariam' \\ Atalay Mulu Fentie $\mathbb{D}^{\prime}$
}

'Tikur Anbessa Specialized Hospital, School of Pharmacy, College of Health Sciences, Addis Ababa University, Addis Ababa, Ethiopia; ${ }^{2}$ Tikur Anbessa Specialized Hospital, Adult Oncology Center, School of Medicine, College of Health Sciences, Addis Ababa University, Addis Ababa, Ethiopia
Correspondence: Atalay Mulu Fentie PO Box: 1176

Tel +251923295462

Email atalay.mulu@aau.edu.et
Background: Cancer is one of the leading causes of morbidity and mortality in the world. It results in considerable mental, physical, and emotional stress for patients. Because of the nature and impact of the disease, and its treatment, measurements of patient satisfaction are important to bring to the attention of health-care providers in order to improve care.

Objective: To assess patient satisfaction at the adult oncology center of Tikur Anbessa Specialized Hospital, Ethiopia using the EORTC PATSAT-C33 tool.

Methods: A facility-based cross-sectional study was conducted from January 2019 to May 2019. A consecutive sampling technique was employed to recruit a total of 384 study participants. Informed consent was obtained for each participant and data were collected using an intervieweradministered questionnaire. Ethical clearance and approval of the study protocol were obtained from the institutional ethics review board of the school of pharmacy. Descriptive statistics was used to summarize the data, while multivariate linear regression analysis was employed to explore factors affecting patient satisfaction. $P<0.05$ was considered as statistically significant.

Results: Among a total of 384 study participants, the majority were female $(65.9 \%)$ and the median age was 49 years. In most $(65.9 \%)$ participants, the health-care service cost was covered by patients themselves; the majority of them were treated for gynecological malignancy (37.2\%) and most received chemotherapy + surgery $(37.2 \%)$. The mean score for the EORTC-PATSAT33 scales for overall satisfaction was 44.8 out of 100 . Place of residence, gender, type of cancer, duration since treatment started, age and source of health-care costs were factors associated with patient satisfaction and all together explained $83 \%$ (adjusted $R$ square $=0.830, P<0.0001$ ) of variance. Of these, residence (where patients came from) accounted for most $(78.7 \%)$ of the variance (adjusted $R$ square $=0.787, P<0.0001)$.

Conclusion: The mean overall satisfaction of patients with the services provided at the outpatient adult oncology center of TASH was significantly lower than previously reported in the world literature, which was $>70$. Hence, a concerted effort must be made to understand and improve patient satisfaction in oncology health-care services in Ethiopia.

Keywords: adult oncology, cancer care, patient satisfaction, EORTC PATSAT-C33

\section{Introduction}

Cancer is the leading cause of morbidity and mortality in both developed and developing nations ${ }^{1}$ and results in considerable mental, physical, and emotional stress in patients. ${ }^{2,3}$ It requires major adjustments to be made in many key areas of 
patients' lives. In addition, the demands on health-care providers to satisfy the complex care needs of patients with cancer have increased manifold and has been recognized as one of the key indicators of health-care quality. Particularly in developed countries, patient satisfaction with care is now being used by health-care institutions to monitor the quality of care provided, gaining accreditation and as a marketing strategy. ${ }^{4,5}$ Patient satisfaction has also an impact on patient compliance with treatment and clinic appointment attendance. Satisfied patients are more likely to continue using the health-care services and have good adherence to services or treatment regimens. ${ }^{6}$ Hence, to improve understanding and care provided by health-care providers, measuring and sharing patient satisfaction reports is very important. In many countries, satisfaction among patients treated for cancer was reported as poor. ${ }^{5,7-11}$ The problem is especially magnified in developing countries like Ethiopia, due to the low socio-economic status of the patients. Also, the limited number of centers for cancer treatment in Ethiopia worsens the problem. In fact in Ethiopia, the study setting, Tikur Anbessa Specialized Hospital (TASH) is the only public center in the country that provides comprehensive cancer treatment. Due to this and other reasons such as poor health-seeking behavior and preferring traditional healers, most patients in Ethiopia were diagnosed with cancer at an advanced stage. ${ }^{3,12}$ The hospital also has limited resources for diagnostic work-up and treatment, and most patients are unable to cover these costs in private clinics or hospitals. Even after making a diagnosis, both documented and other informal reports from the center showed that patients died while waiting for their appointment, especially for radiation therapy. Defaulting on treatment is also common in the center because most patients cannot afford the services, and they have to travel long distances from different parts of the country and cannot afford the associated costs of travel. In addition, living and hotel accommodation costs in Addis Ababa are extremely high. ${ }^{13}$

Hence, the purpose of the current study was to assess the level of patient satisfaction towards services provided by the hospital and associated factors affecting patient satisfaction at the adult oncology center of TASH.

\section{Methods}

The study was conducted at the adult oncology center of TASH, which was established in 1972. It is the largest teaching public hospital affiliated with the College of
Health Sciences, Addis Ababa University and serves as a training center for undergraduate and postgraduate medical, pharmacy, and other health science students. The hospital has around 465 physicians, 76 pharmacists, 992 nurses, and 115 other health-care professionals. It also has 950 administrative and support staff. The Hospital has about 700 beds and serves more than 500,000 patients per year in its 20 outpatient specialty clinics, inpatient, and emergency departments. Overall, the adult oncology center serves more than 850 patients per month and around 10,000 patients per year. Specialized comprehensive and clinical services, which are not available in other public or private institutions, are offered to the whole nation by this hospital, eg, radiation therapy for cancer.

\section{Study Design and Period}

A facility-based cross-sectional study was conducted from January 2019 to May 2019 at the adult oncology unit of TASH using the EORTC PATSAT-C33 tool. ${ }^{14}$ All consenting patients who attended the center and fulfilled the inclusion criteria during the study period were included in the study.

\section{Inclusion and Exclusion Criteria}

Eligible patients included: all outpatients (i) who were visiting the adult oncology center of TASH during the study period with a histologically confirmed diagnosis for cancer; (ii) who had already started treatment (ie, at least greater than or equal to one cycle of chemotherapy, 2-6 weeks of radiotherapy, at least two cycles of targeted therapy, or follow-up care in the past 3-24 months); ${ }^{14}$ (iii) who were willing to participate; and (iv) who were aged $\geq 18$ years old. Patients who had not yet started treatment or who had any cognitive impairment were excluded from the study.

\section{Sample Size Determination and Sampling Procedure}

A single population proportion formula ${ }^{15}$ was used to calculate the sample size with the assumption that the overall prevalence of satisfied patients is $50 \%$ with a margin of error of $5 \%$, a confidence level of $95 \%$, and a detection power of $80 \%$. Based on the power calculation and sample size needed to demonstrate satisfaction, a total of 384 study participants were recruited to the study. The $50 \%$ prevalence was chosen due to the lack of similar published studies conducted in Ethiopia and Africa. 
A consecutive sampling technique was used to recruit the study participants and all those who agreed were approached for written informed consent until the sample of 384 participants was reached.

\section{Data Collection and Management}

Data were collected using a data abstraction format and the 2017 newly updated European Organization for Research and Treatment of Cancer (EORTC) PATSATC33 questionnaire. ${ }^{14}$

\section{(i) Data abstraction format}

The data abstraction format was designed to extract information from a medical chart or directly from the patient, such as socio-demographic characteristics (age, gender, marital status, educational level, region, place of residence, source of treatment, and employment status), as well as clinical characteristics, including primary cancer diagnosis, type of cancer treatment (ie, chemotherapy, radiotherapy, surgery, or a combination of these), and patient performance status documented by treating physician using Eastern Cooperative Oncology Group (ECOG) scale. Clinical characteristics were extracted from patient medical records.

\section{(ii) EORTC PATSAT-C33}

The EORTC PATSAT-C33 is a 33-item questionnaire that is reliable, validated internationally, and widely used in assessing patients' appraisal towards services provided by hospital doctors, nurses, and radiotherapy technicians. It is also used to assess specific organizational and structural aspects of the service delivery and to highlight aspects of care needing improvement in the outpatient oncology setting.

Each item is rated on a 5-point Likert scale ( $1=$ "poor," 2="fair," 3="good," 4="very good," and 5= "excellent"). The interviewers were trained data collectors who had received brief training. This questionnaire was first translated from its original English language version into Amharic by a bilingual person who speaks Amharic and English fluently. A second bilingual translator who had not seen the original English version back-translated the instrument from the Amharic version into English. The two English translation versions were then compared for equivalence. If the back-translated items and the originals did not agree, this process was repeated until the back- translated and the original versions were congruous. Following that, pre-testing was done in 10 selected patients treated for cancer.

The satisfaction responses were categorized into satisfaction towards doctors' technical skills (items 1-3), information exchange (items 4-6) and affective behavior (items 7-10); overall satisfaction with nurses or radiotherapy technologists (items 11-17), coordination (items 1821 ), interaction with all hospital staff (items 22-28), and hospital organization and environment (items 18-32); and finally overall satisfaction with the hospital (items 1-33). Then, the mean score for each subcategory was calculated and transformed into a 0-100 scale using 100/(maximum score - no. of items) x (sum of means - no. of items). The higher scores indicated a higher satisfaction level and vice versa.

\section{Data Analysis}

Data were entered and analyzed using SPSS version-20. Descriptive statistics, including frequency, median, and range, were used to summarize socio-demographic data, clinical, and treatment-related characteristics.

Subgroup analyses were made using Student's unpaired $t$-test and one-way ANOVA to compare two groups and three or more groups in the analysis of patient satisfaction. Multiple linear regression analysis was performed to determine possible predictors of patient satisfaction. A univariate analysis was conducted to obtain candidate variables for the multivariate regression models to determine possible predictors of the outcome variable. For multi-categorical independent variables, dummy variable coding was performed. The association between continuous or binary variables and overall patient satisfaction was tested for significance by calculating Pearson correlation coefficients. These candidate variables must fulfill either of the two criteria. The first criterion was having a $P$-value of $<0.3$ and the magnitude of the correlation coefficient $>0.3$. The second criterion was whether the variables were clinically significant enough to be included even though it did not meet the first criterion partially or completely. A predictor variable was considered a candidate for multiple regression analysis if it had at least a marginal association of $P<0.3$ and a correlation coefficient of $r=0.3$. A cutoff value of 0.3 was used initially and then decreased to 0.05 in the multivariate linear regression model to identify strong predictors associated with patient satisfaction. Possible collinearity problems were addressed by examining the tolerance of all independent variables. 
A multivariate linear regression analysis was conducted using forward and stepwise methods and cross-validated using hierarchical clinical and symptom models. A $P$-value $<0.05$ was considered as statistically significant.

\section{Results}

\section{Socio-Demographic Characteristics}

Among a total of 384 study participants, the majority (65.9\%) were female. Regarding age distribution, the median age of study participants was 49 years (ranging from 19 to 76 years). Most (67.2\%) were married. A significant proportion of the participants $(60.2 \%)$ were from outside of Addis Ababa. For most participants (65.9\%) the healthcare service cost was covered by patients themselves or their relatives. About $31.5 \%$ completed higher education and $26.3 \%$ cannot read and write, these accounted for the largest proportion of the study participants (Table 1).

\section{Disease-Related Characteristics and Treatment History}

Most (31.0\%) study participants were diagnosed and treated for gynecological malignancy, followed by head and neck malignancy (17.4\%). A significant proportion of participants' performance status was either ECOG-1 (37\%) or $2(34.6 \%)$. Regarding treatment history, the majority of the study participants received chemotherapy + surgery $(37.2 \%),<6$ months since treatment started $(66.2 \%)$, and the diagnosis was made (50.3\%) (Table 2).

\section{Level of Patient Satisfaction}

Most of the study participants reported that services provided by doctors with respect to each domain were good (32.6$35.7 \%$ ) or very good (25.5-29.2\%); whereas the overall services provided by nurses were good $(36.9 \%)$ or fair (22.1\%). Regarding the coordination of hospital care service, the majority of patients ranked the hospital as fair (32.8\%) or good (32.0\%). Most rated the interaction of hospital heath workers with other health-care team members as good $(38.0 \%)$ or fair $(32.8 \%)$. The opportunity for the family to be involved in their care was rated as good (33.6\%). But with respect to the ease of access to parking, means of transport, and the environment of the building like cleanness, spaciousness, and calmness, most participants rated these as fair or poor. The overall care provided by the hospital was rated as good $(34.9 \%)$ or fair $(29.7 \%)$. Regarding the interaction with other health-care team members, most of the patients were less satisfied with the waiting time to obtain results of
Table I Socio-Demographics Characteristics of Participants, Tikur Anbessa Specialized Hospital Addis Ababa, Ethiopia

\begin{tabular}{|c|c|c|}
\hline Variable, $N=384$ & Frequency & Percentage \\
\hline \multicolumn{3}{|l|}{ Sex } \\
\hline Female & 253 & 65.9 \\
\hline Male & $|3|$ & 34.1 \\
\hline \multicolumn{3}{|c|}{$\begin{array}{l}\text { Age in years (median age } 49 \text { years, } \\
\text { range } 19-76 \text { years) }\end{array}$} \\
\hline$<40$ & 125 & 32.6 \\
\hline $40-49$ & 68 & 17.7 \\
\hline $50-59$ & 101 & 26.3 \\
\hline $60-70$ & 75 & 19.5 \\
\hline$>70$ & 15 & 3.9 \\
\hline \multicolumn{3}{|l|}{ Marital status } \\
\hline Married & 258 & 67.2 \\
\hline Single* & 126 & 32.8 \\
\hline \multicolumn{3}{|l|}{ Educational level } \\
\hline Unable to read and write & 101 & 26.3 \\
\hline Only read and write & 26 & 6.8 \\
\hline Primary education & 63 & 16.4 \\
\hline Secondary education & 73 & 19 \\
\hline Higher education & 121 & 31.5 \\
\hline \multicolumn{3}{|l|}{ Residence } \\
\hline Out of Addis Ababa & 231 & 60.2 \\
\hline Addis Ababa & 153 & 39.8 \\
\hline \multicolumn{3}{|l|}{ Health service charge } \\
\hline With $\operatorname{cash}^{\$}$ & 253 & 65.9 \\
\hline With free ${ }^{\#}$ & $|3|$ & 34.1 \\
\hline \multicolumn{3}{|l|}{ Occupational status } \\
\hline Self-employed & 112 & 29.2 \\
\hline Housewife & 103 & 26.8 \\
\hline Government employed & 75 & 19.5 \\
\hline Farmer & 35 & 9.1 \\
\hline Merchant & 27 & 7.0 \\
\hline Others** & 32 & 8.3 \\
\hline
\end{tabular}

Notes: *Unmarried, divorced, and widowed; **student, unemployed, and retired, single; ${ }^{\$}$ those patients whose health-care services cost in the hospital is covered by the patient themselves and/or their relatives; " those patients who received any health-care services available in the hospital with the expense of the hospital itself.

medical tests $(38.8 \%)$ and also about the waiting time to undergo medical tests and/or treatment (46.1\%). The kindness and helpfulness of the technical, reception, laboratory personnel, etc., were rated as fair (28.1\%) (Table 3).

\section{Mean Scores of EORTC PATSAT-C33 Among Patients Treated for Cancer}

For the evaluation of doctors with regard to their technical skills, information exchange, and affective behavior, domain 
Table 2 Disease-Related Characteristics and Treatment History of Participants, Tikur Anbessa Specialized Hospital Addis Ababa, Ethiopia

\begin{tabular}{|c|c|c|}
\hline Variables, $N=384$ & Frequency & Percentage \\
\hline \multicolumn{3}{|l|}{ Disease location (tumor site) } \\
\hline Gynecological cancer & 119 & 31 \\
\hline Head and neck cancer & 67 & 17.4 \\
\hline Breast cancer & 60 & 15.6 \\
\hline Gl & 53 & 13.8 \\
\hline Sarcoma & 31 & 8.1 \\
\hline Lung & 20 & 5.2 \\
\hline Lymphoma & 18 & 4.7 \\
\hline Others* & 16 & 4.2 \\
\hline \multicolumn{3}{|l|}{ Types of treatment } \\
\hline Chemotherapy + surgery & 143 & 37.2 \\
\hline Chemotherapy only & 112 & 29.2 \\
\hline $\mathrm{RT}+$ surgery & 34 & 8.8. \\
\hline Chemotherapy + RT & 29 & 7.6 \\
\hline RT only & 27 & 7.0 \\
\hline Chemotherapy + RT and surgery & 21 & 5.5 \\
\hline Surgery only & 18 & 4.7 \\
\hline \multicolumn{3}{|l|}{ ECOG status } \\
\hline 0 & 64 & 16.7 \\
\hline 1 & 142 & 37 \\
\hline 2 & 133 & 34.6 \\
\hline 3 & 44 & 11.5 \\
\hline \multicolumn{3}{|l|}{$\begin{array}{l}\text { Duration since treatment started in } \\
\text { months }\end{array}$} \\
\hline$<6$ month & 255 & 66.2 \\
\hline $6-12$ month & 67 & 17.4 \\
\hline$>12$ month & 62 & 16.4 \\
\hline \multicolumn{3}{|l|}{$\begin{array}{l}\text { Duration since diagnosis of cancer } \\
\text { made in months }\end{array}$} \\
\hline$<6$ month & 193 & 50.3 \\
\hline $6-12$ month & 102 & 26.6 \\
\hline$>12$ month & 89 & 23.2 \\
\hline
\end{tabular}

Note: Others*: prostate, bone, bladder, liver, and nerve cancer. Abbreviations: RT, radiation treatment; ECOG, Eastern Cooperative Oncology Group.

mean scores of participants were $52.6(\mathrm{SD}=25.2), 50.2$ $(\mathrm{SD}=25.8)$ and $52.0(\mathrm{SD}=24.3)$; whereas domain mean score with respect to overall satisfaction towards nurses or radiation-therapy technologists was $46.2(\mathrm{SD}=24.7)$. For the hospital organization or physical environment, the domain mean scores ranged from 33.7 to 46.4, whereas overall satisfaction towards hospital care was 40.7 ( $\mathrm{SD}=19.2)$. In general, the domain mean overall satisfaction score was 44.8 out of $100(\mathrm{SD}=19.5)$. The domain median with minimum and the maximum score is also presented in Table 4.

\section{Correlation Analysis of Overall Patient Satisfaction and Sub-Groups}

The items categorized with respect to doctors, nurses, and radiotherapy technologists and hospital organization and environment in the study were significantly correlated with the overall patient satisfaction towards TASH outpatient oncology services. Among the seven subgroups, patients' interaction with health-care team members with overall patient satisfaction was highly positively correlated and the highest and; ranked as number 1 with Pearson correlation coefficient of 0.950 , whereas doctors' information exchange was ranked as lowest with Pearson correlation coefficient of 0.632 ( $r$-value from 0.7 to 1.0 indicates a strong positive linear relationship). All the items were statistically significant at the level of $<0.0001$ (Table 5).

\section{Factors Associated with Patient Satisfaction}

The results of the comparative statistical analysis for mean scores of EORTC PATSAT-C33 domains of patient satisfaction according to the categorical socio-demographic and clinical characteristics variables are shown in Table 6. The overall satisfaction domain that constitute doctors' technical skills, doctors' information exchange, doctors' affective behavior, overall satisfaction towards nurses and radiology technologist services, coordination, interaction with health-care teams and overall satisfaction towards hospital organization and environment; lower scores of EORTC PATSAT-C33 were associated with being female $(p<0.0001)$, older age $(P=0.031)$, being from out of Addis Ababa where the treatment center is found $(P<0.0001)$, among patients treated for gynecological malignancy $(P<0.0001)$, those whose health-care service cost was covered by the patient themselves or their relatives $(P=0.013)$ and $<6$ months since treatment started.

\section{Correlating Factors Affecting Patient}

\section{Satisfaction}

\section{Univariate Analysis}

In bivariate analysis, among 13 investigated variables, 9 showed an association with patient satisfaction measured by the EORTC-PATSAT-C33 scale. These variables were utilized in multivariate linear regression analysis. Of these candidate variables, 8 were categorical; 3 of them were binary (gender, residence, and source of healthcare cost); and the remaining 5 were multi-categorical variables (educational level, ECOG status, type of cancer, duration since 
Table 3 Evaluation of Patient Satisfaction With Doctors, Nurses, and Radiotherapy Technologists, and Overall Tikur Anbessa Specialized Hospital Services, Addis Ababa, Ethiopia

\begin{tabular}{|c|c|c|c|c|c|}
\hline $\begin{array}{l}\text { Variables } \\
N=384, \text { n (\%) }\end{array}$ & Poor & Fair & Good & $\begin{array}{l}\text { Very } \\
\text { Good }\end{array}$ & Excellent \\
\hline Doctors' technical skills (items I-3) & $8(2.1)$ & $72(18.8)$ & $133(34.6)$ & $112(29.2)$ & $59(15.4)$ \\
\hline Doctors' information exchange (items 4-6?) & $15(3.9)$ & $74(19.3)$ & $125(32.6)$ & III (28.6) & $59(15.4)$ \\
\hline Doctors' affective behavior (items 7-10?) & $6(1.6)$ & $60(15.6)$ & $137(35.7)$ & $98(25.5)$ & $83(21.6)$ \\
\hline Overall satisfaction with nurses' service (items II-I7?), N=208 & $5(2.4)$ & $46(22.1)$ & $90(43.3)$ & $41(19.7)$ & $26(12.5)$ \\
\hline Overall satisfaction with radiology technologists' service (items II-I7), N=I76 & $3(1.7)$ & $40(22.7)$ & $65(36.9)$ & $4 \mathrm{I}(23.3)$ & $27(15.3)$ \\
\hline Coordination (items $|8-2|$ ?) & $6(1.6)$ & $126(32.8)$ & $123(32.6)$ & $82(21.4)$ & $47(12.2)$ \\
\hline Interaction with health-care teams (items 22-28?) & $3(0.8)$ & $126(32.8)$ & $146(38.0)$ & $90(23.4)$ & $19(4.9)$ \\
\hline \multicolumn{6}{|l|}{ Single items } \\
\hline Opportunity to be involved in their care (item 29?) & $47(12.8)$ & $100(26.0)$ & $129(33.6)$ & $77(20.1)$ & $31(8.1)$ \\
\hline Ease of access to the hospital (item 30 ?) & $95(24.7)$ & $138(35.9)$ & $94(24.5)$ & $36(9.4)$ & $21(5.5)$ \\
\hline Ease of finding different departments (item $3 \mid$ ?) & $84(21.9)$ & $138(35.9)$ & $112(29.2)$ & $31(8.1)$ & $19(4.9)$ \\
\hline Environment of the building (item 32?) & $103(26.8)$ & $115(29.9)$ & $94(24.5)$ & $45(11.7)$ & $27(7.0)$ \\
\hline In general, how do you rate the care you received from the hospital (item 33?) & $48(12.5)$ & $114(29.7)$ & $134(34.9)$ & $67(17.4)$ & $21(5.5)$ \\
\hline \multicolumn{6}{|l|}{ Special concern items } \\
\hline $\begin{array}{l}\text { The kindness and helpfulness of the technical, reception, laboratory personnel, } \\
\text { etc (item 22?) }\end{array}$ & $106(27.6)$ & $108(28.1)$ & $87(22.7)$ & $60(15.6)$ & $23(6.0)$ \\
\hline The waiting time for obtaining results of medical tests (item 26) & $149(38.8)$ & $101(26.3)$ & $76(19.8)$ & $38(9.9)$ & $20(5.2)$ \\
\hline The waiting time for undergoing medical tests and/or treatments (item 27?) & $177(46.1)$ & 89 (23.2) & 65 (16.9) & $31(8.1)$ & $22(5.7)$ \\
\hline
\end{tabular}

treatment started and a diagnosis made); and one was a continuous variable (age).

\section{Multivariate Linear Regression Analysis}

Among the nine variables utilized for multivariate linear regression analysis, six variables (residence, gender, type of cancer, duration since treatment started, age, and source of health-care costs) (Table 7) were correlated with patient satisfaction through stepwise and forward methods of multivariate linear regression and cross-validated by a hierarchical regression method. All the correlated variables together explained $83 \%$ (adjusted $R$ square $=0.830$,

Table 4 Mean Scores of EORTC PATSAT-C33 Among Patients Treated for Cancer at Tikur Anbessa Specialized Hospital

\begin{tabular}{|c|c|c|c|c|}
\hline Variables & $\begin{array}{l}\text { Likert Scale } \\
\text { Mean } \pm \text { SD }\end{array}$ & $\begin{array}{l}\text { Formula for Domain } \\
\text { Mean* }\end{array}$ & $\begin{array}{l}\text { Domain Mean } \\
\pm \text { SD of } 100\end{array}$ & $\begin{array}{l}\text { Domain Median } \\
\text { (Range) }\end{array}$ \\
\hline Doctors' technical skills (items I-3?) & $3.0 \pm 1.02$ & $100 /(15-3) \times(9.2-3)$ & $52.6 \pm 25.5$ & $50.0(2.9-100)$ \\
\hline Doctors' information exchange (items 4-6?) & $3.0 \pm 1.03$ & $100 /(15-3) \times(9-3)$ & $50.2 \pm 25.8$ & $47.6(1.8-99.2)$ \\
\hline Doctors' affective behavior (items 7-10?) & $3.1 \pm 0.97$ & $100 /(20-3) \times(12.3-3)$ & $52.0 \pm 24.3$ & $51.0(2.3-100)$ \\
\hline $\begin{array}{l}\text { Overall satisfaction with nurses' and radiology } \\
\text { technologist's service (items II-I7?) }\end{array}$ & $2.8 \pm 0.99$ & $100 /(35-3) \times(19.9-3)$ & $46.2 \pm 24.7$ & $46.4(1.9-100)$ \\
\hline Coordination (item $|8-2|$ ?) & $2.7 \pm 0.92$ & $100 /(20-3) \times(10.8-3)$ & $42.5 \pm 22.9$ & $37.5(1.2-90.7)$ \\
\hline Interaction with health-care teams (item 22-28?) & $2.6 \pm 0.84$ & $100 /(35-5) \times(18-5)$ & $39.5 \pm 20.9$ & $36.9(1.1-97.3)$ \\
\hline \multicolumn{5}{|l|}{ Single items } \\
\hline Opportunity to be involved in their care (item 29?) & $2.9 \pm 1.12$ & $100 /(5-1) \times(2.9-1)$ & $46.4 \pm 28.0$ & $50.1(1.4-100)$ \\
\hline Ease of access of the hospital (item 30?) & $2.3 \pm 1.11$ & $100 /(5-1) \times(2.3-1)$ & $33.7 \pm 27.8$ & $22.1(1.0-99.0)$ \\
\hline Ease of finding different departments (item $3 \mathrm{I}$ ?) & $2.4 \pm 1.06$ & $100 /(5-1) \times(2.4-1)$ & $34.6 \pm 26.6$ & $24.9(1.0-88.9)$ \\
\hline Environment of the building (item 32?) & $2.4 \pm 1.20$ & $100 /(5-1) \times(2.4-1)$ & $35.5 \pm 30.0$ & $25.7(1.0-100)$ \\
\hline Overall satisfaction towards hospital care (items I8-32?) & $2.6 \pm 0.77$ & $100 /(80-16) \times(41.6-16)$ & $40.4 \pm 19.2$ & $38.3(1.56-96)$ \\
\hline Mean overall satisfaction (items I-33?) & $2.79 \pm 0.78$ & $100 /(165-33) \times(92.11-33)$ & $44.8 \pm 19.5$ & $43.9(1.7-94.9)$ \\
\hline
\end{tabular}

Note: *Domain mean transformed to $100=100 /($ maximum score - no. of items) $\times$ (sum of means - no. of items) 
Table 5 Ranking of Item Groups in Terms of Their Priority Towards Patient Satisfaction

\begin{tabular}{|c|c|c|c|c|c|}
\hline S.N & Item Domain & $\begin{array}{l}\text { Pearson Correlation } \\
\text { Coefficient }\end{array}$ & $\begin{array}{l}\text { P-value } \\
\text { (2-Tailed) }\end{array}$ & $\mathbf{N}$ & Rank \\
\hline I. & Overall satisfaction (items I-33?) & I & $<0.0001$ & 384 & \\
\hline 2. & Interaction with healthcare teams (items 22-28?) & 0.950 & $<0.0001$ & 384 & I \\
\hline 3. & $\begin{array}{l}\text { Overall satisfaction with hospital organization and environment } \\
\text { (items 18-32?) }\end{array}$ & 0.942 & $<0.0001$ & 384 & 2 \\
\hline 4. & Coordination (items $|8-2|$ ?) & 0.887 & $<0.000$ I & 384 & 3 \\
\hline 5. & $\begin{array}{l}\text { Overall satisfaction with nurses' \& radiology technologists' service } \\
\text { (items II-I7?) }\end{array}$ & 0.750 & $<0.000$ I & 384 & 4 \\
\hline 6. & Doctors' affective behavior (items 7-10?) & 0.713 & $<0.0001$ & 384 & 5 \\
\hline 7. & Doctors' technical skills (items I-3?) & 0.646 & $<0.0001$ & 384 & 6 \\
\hline 8. & Doctors' information exchange (items 4-6?) & 0.632 & $<0.0001$ & 384 & 7 \\
\hline
\end{tabular}

$P<0.0001)$ of the variance. Of these, place of residence (where patients come from) accounted for $78.7 \%$ of the variance (adjusted $R$ square $=0.787, P<0.0001$ ).

For the current model, the values of variance inflation factor (VIF) for all independent variables were $<10$. Tolerance (1 divided by VIF) of all independent variables ranged from 0.43 to 0.81 . Thus, multicollinearity problems did not exist in the models since all tolerance values were above 0.2 and the average VIF was very close to 1 . All standardized residuals in the models were normally distributed $(P<0.05)$, meeting the assumptions of the linear regression model. The multiple linear equation became: predicted overall patient satisfaction score $=13.80+9.72$ (being from Addis Ababa) +-3.66 (female) +-2.33 (gynecological malignancy) $+-0.91 \quad(<6$-month since treatment started) +0.86 (age) +0.72 (being health-careassociated costs are covered by the government). Making other predictor variables in the equation constant, the interpretation for the result in the equation is as follows. The value indicated that as the number of residents in Addis Ababa increases by one, the overall satisfaction of patients treated at the adult oncology center increases by 9.72 units. However, as the number of females and patients treated for gynecological malignancy increased by one, overall satisfaction decreases by 3.66 units and 2.33 units, respectively.

\section{Discussion}

The present study aimed to assess patient satisfaction in the oncology services towards doctors, nurses, radiology technologists, rate of services \& care organization, and to identify possible associated factors affecting patient satisfaction in the adult oncology center of the hospital. Patient satisfaction has an important role in improving treatment outcomes and quality of care in the service delivery system. ${ }^{16}$ However, in this study, we found that the satisfaction level of Ethiopian patients treated for cancer is low. Patient experience of care evaluation is essential to provide the opportunity for improvement of health services, since feedback from the patient's perspective is a benchmark for health-care quality improvement. Place of residence, type of malignancy, sex, sources of healthcare cost, and age were significantly associated with overall patient satisfaction.

The present study revealed that the mean score of overall patient satisfaction at the outpatient adult oncology center of TASH was 44.8. This finding was significantly lower than previously reported studies in France (72.5), ${ }^{17}$ Japan (80.6-84.7), ${ }^{18}$ Spain (84.3), ${ }^{19}$ Bulgaria (88.5), ${ }^{7}$ USA (89.4), ${ }^{8}$ and Australia (>95). ${ }^{11}$ This difference might be due to the low socioeconomic status of our patients in particular and the country Ethiopia at large advanced stage of cancer at the time of diagnosis and the presence of only one oncology center providing comprehensive cancer care. Furthermore, the lack of availability of accessible cost-free or affordable diagnostic procedures and frequently low stock of anticancer drugs in the oncology center of TASH might contribute to low satisfaction levels in this study. The problem is also aggravated by the costly nature of most anticancer drugs.

Most of the current study participants reported low satisfaction levels with hospital staff interaction, coordination, organization, and environment of the hospital (mean score: 33.7-46.4) compared to satisfaction with doctors (mean score: 50.2-52.6), and doctors' information exchange was the domain least correlated with overall patient satisfaction, with a Pearson correlation coefficient of 0.632. In addition, health-care aspects, in particular waiting time for 
Table 6 Comparative Statistical Analysis of EORTC PATSAT-C33 Domain Mean Scores Among Patients Treated for Cancer at Tikur Anbessa Specialized Hospital, According to the Categorical Socio-Demographic and Clinical Characteristics

\begin{tabular}{|c|c|c|c|c|c|c|c|c|c|}
\hline \multicolumn{2}{|c|}{ Variables, Mean \pm SD } & os & DTS & DIE & DAB & SNRT & Coordination & IHCT & OSTHOE \\
\hline Sex & $\begin{array}{l}\text { Male } \\
\text { Female } \\
P \text {-value }\end{array}$ & $\begin{array}{l}44.7 \pm 9.4 \\
34.8 \pm 9.6 \\
<0.0001\end{array}$ & $\begin{array}{l}50.1 \pm 7.5 \\
43.9 \pm 11.5 \\
0.004\end{array}$ & $\begin{array}{l}48.3 \pm 4.7 \\
47.1 \pm 3.4 \\
0.308\end{array}$ & $\begin{array}{l}53.3 \pm 8.9 \\
51.4 \pm 5.0 \\
0.461\end{array}$ & $\begin{array}{l}44.7 \pm 25.6 \\
47.0 \pm 24.3 \\
0.393\end{array}$ & $\begin{array}{l}43.4 \pm 12.1 \\
33.9 \pm 16.1 \\
<0.0001\end{array}$ & $\begin{array}{l}40.5 \pm 10.9 \\
35.9 \pm 12.1 \\
0.001\end{array}$ & $\begin{array}{l}37.1 \pm 10.1 \\
29.7 \pm 11.0 \\
<0.0001\end{array}$ \\
\hline Age in years & $\begin{array}{l}<40 \\
40-49 \\
50-59 \\
60-69 \\
\geq 70 \\
P \text {-value }\end{array}$ & $\begin{array}{l}42.7 \pm 9.5 \\
47.6 \pm 11.7 \\
43.7 \pm 12.9 \\
48.2 \pm 11.9 \\
39.7 \pm 11.2 \\
0.031\end{array}$ & $\begin{array}{l}50.5 \pm 16.3 \\
55.1 \pm 18.6 \\
51.2 \pm 14.7 \\
54.4 \pm 11.5 \\
42.8 \pm 16.3 \\
0.374\end{array}$ & $\begin{array}{l}48.3 \pm 16.7 \\
53.5 \pm 18.1 \\
46.9 \pm 14.8 \\
54.4 \pm 14.0 \\
50.6 \pm 11.2 \\
0.243\end{array}$ & $\begin{array}{l}49.8 \pm 13.4 \\
54.1 \pm 16.3 \\
50.1 \pm 15.3 \\
57.9 \pm 12.7 \\
44.6 \pm 9.6 \\
0.012\end{array}$ & $\begin{array}{l}43.1 \pm 13.8 \\
50.4 \pm 16.1 \\
45.3 \pm 14.7 \\
49.0 \pm 14.9 \\
46.2 \pm 4.7 \\
0.282\end{array}$ & $\begin{array}{l}39.6 \pm 12.2 \\
44.3 \pm 15.6 \\
42.8 \pm 13.2 \\
49.9 \pm 9.8 \\
38.8 \pm 6.9 \\
0.047\end{array}$ & $\begin{array}{l}37.4 \pm 11.2 \\
48.2 \pm 12.3 \\
38.1 \pm 9.8 \\
43.1 \pm 10.9 \\
30.7 \pm 7.6 \\
0.031\end{array}$ & $\begin{array}{l}36.0 \pm 18.9 \\
38.2 \pm 21.2 \\
35.4 \pm 18.5 \\
34.0 \pm 19.5 \\
28.3 \pm 22.5 \\
0.803\end{array}$ \\
\hline Marital status & $\begin{array}{l}\text { Married } \\
\text { Single } \\
P \text {-value }\end{array}$ & $\begin{array}{l}45.1 \pm 9.7 \\
44.2 \pm 9.0 \\
0.699\end{array}$ & $\begin{array}{l}49.5 \pm 14.8 \\
56.9 \pm 16.3 \\
0.008\end{array}$ & $\begin{array}{l}50.5 \pm 15.1 \\
49.5 \pm 17.4 \\
0.719\end{array}$ & $\begin{array}{l}52.4 \pm 14.1 \\
51.2 \pm 14.9 \\
0.656\end{array}$ & $\begin{array}{l}46.7 \pm 15.7 \\
45.3 \pm 12.6 \\
0.615\end{array}$ & $\begin{array}{l}42.9 \pm 13.1 \\
41.6 \pm 12.7 \\
0.587\end{array}$ & $\begin{array}{l}40.3 \pm 11.3 \\
37.8 \pm 10.3 \\
0.276\end{array}$ & $\begin{array}{l}36.6 \pm 20.1 \\
44.2 \pm 19.8 \\
0.313\end{array}$ \\
\hline Residence & $\begin{array}{l}\text { AA } \\
\text { Out of AA } \\
P \text {-value }\end{array}$ & $\begin{array}{l}49.2 \pm 8.7 \\
32.6 \pm 9.8 \\
<0.0001\end{array}$ & $\begin{array}{l}53.3 \pm 15.3 \\
49.9 \pm 15.7 \\
0.197\end{array}$ & $\begin{array}{l}46.9 \pm 14.1 \\
52.3 \pm 16.8 \\
0.048\end{array}$ & $\begin{array}{l}50.4 \pm 14.0 \\
53.1 \pm 14.5 \\
0.287\end{array}$ & $\begin{array}{l}46.7 \pm 15.1 \\
45.5 \pm 14.5 \\
0.645\end{array}$ & $\begin{array}{l}49.0 \pm 12.6 \\
40.1 \pm 13.4 \\
0.001\end{array}$ & $\begin{array}{l}41.4 \pm 11.5 \\
32.6 \pm 9.9 \\
<0.0001\end{array}$ & $\begin{array}{l}41.2 \pm 7.4 \\
29.1 \pm 9.1 \\
<0.0001\end{array}$ \\
\hline Cancer type & $\begin{array}{l}\text { Gynecological } \\
\text { Head and neck } \\
\text { Breast } \\
\text { Gl } \\
\text { Sarcoma } \\
\text { Lung } \\
\text { Lymphoma } \\
\text { Others } \\
\text { p-value }\end{array}$ & $\begin{array}{l}39.9 \pm 10.6 \\
41.6 \pm 9.0 \\
47.9 \pm 8.3 \\
48.9 \pm 9.6 \\
47.3 \pm 9.2 \\
43.1 \pm 7.2 \\
54.3 \pm 19.7 \\
46.0 \pm 17.3 \\
<0.0001\end{array}$ & $\begin{array}{l}47.8 \pm 16.8 \\
46.8 \pm 13.6 \\
61.3 \pm 15.3 \\
55.8 \pm 14.4 \\
49.5 \pm 13.9 \\
45.4 \pm 10.3 \\
61.1 \pm 27.7 \\
58.9 \pm 21.6 \\
0.005\end{array}$ & $\begin{array}{l}46.7 \pm 18.8 \\
46.1 \pm 16.2 \\
56.8 \pm 12.3 \\
53.8 \pm 16.7 \\
53.2 \pm 16.5 \\
48.8 \pm 14.1 \\
57.8 \pm 19.2 \\
42.7 \pm 21.9 \\
0.094\end{array}$ & $\begin{array}{l}45.3 \pm 15.7 \\
47.9 \pm 12.1 \\
62.2 \pm 13.7 \\
56.6 \pm 4.4 \\
55.1 \pm 2.3 \\
50.9 \pm 8.7 \\
56.6 \pm 12.8 \\
56.3 \pm 11.8 \\
0.001\end{array}$ & $\begin{array}{l}45.2 \pm 15.3 \\
44.2 \pm 15.7 \\
46.8 \pm 14.4 \\
49.5 \pm 15.4 \\
42.3 \pm 12.4 \\
47.9 \pm 3.3 \\
50.0 \pm 9.9 \\
50.7 \pm 18.5 \\
0.844\end{array}$ & $\begin{array}{l}39.8 \pm 12.5 \\
41.6 \pm 9.6 \\
45.6 \pm 14.7 \\
47.4 \pm 13.5 \\
47.4 \pm 13.4 \\
42.8 \pm 11.8 \\
47.7 \pm 13.7 \\
41.9 \pm 18.2 \\
0.0018\end{array}$ & $\begin{array}{l}34.8 \pm 8.9 \\
38.8 \pm 10.6 \\
41.8 \pm 12.1 \\
46.8 \pm 9.5 \\
44.6 \pm 0.5 \\
39.6 \pm 12.6 \\
44.1 \pm 13.0 \\
42.2 \pm 8.5 \\
0.007\end{array}$ & $\begin{array}{l}23.6 \pm 17.7 \\
39.9 \pm 18.8 \\
43.3 \pm 20.7 \\
38.3 \pm 21.1 \\
46.7 \pm 22.7 \\
38.3 \pm 15.5 \\
35.6 \pm 17.7 \\
37.9 \pm 15.3 \\
<0.0001\end{array}$ \\
\hline $\begin{array}{l}\text { Type of health- } \\
\text { care cost }\end{array}$ & $\begin{array}{l}\text { Cash } \\
\text { Free } \\
p \text {-value }\end{array}$ & $\begin{array}{l}40.3 \pm 9.97 \\
49 \pm 7.94 \\
0.013\end{array}$ & $\begin{array}{l}51.3 \pm 16.6 \\
58.3 \pm 19.0 \\
0.001\end{array}$ & $\begin{array}{l}48.1 \pm 16.0 \\
53.8 \pm 14.6 \\
0.211\end{array}$ & $\begin{array}{l}51.4 \pm 14.7 \\
56.3 \pm 21.2 \\
0.624\end{array}$ & $\begin{array}{l}43.5 \pm 23.3 \\
50.9 \pm 8.7 \\
0.031\end{array}$ & $\begin{array}{l}39.6 \pm 21.3 \\
46.6 \pm 19.8 \\
0.01\end{array}$ & $\begin{array}{l}35.7 \pm 24.5 \\
44.2 \pm 16.4 \\
0.002\end{array}$ & $\begin{array}{l}29.2 \pm 19.7 \\
38.6 \pm 24.2 \\
<0.0001\end{array}$ \\
\hline $\begin{array}{l}\text { Duration since } \\
\text { treatment } \\
\text { started in } \\
\text { months }\end{array}$ & $\begin{array}{l}<6 \\
6-12 \\
>12 \\
p \text {-value }\end{array}$ & $\begin{array}{l}43.8 \pm 10.0 \\
47.2 \pm 9.8 \\
49.2 \pm 6.5 \\
0.005\end{array}$ & $\begin{array}{l}48.6 \pm 14.3 \\
58.7 \pm 18.5 \\
58.3 \pm 14.4 \\
0.001\end{array}$ & $\begin{array}{l}48.0 \pm 16.7 \\
54.9 \pm 15.4 \\
53.6 \pm 11.8 \\
0.076\end{array}$ & $\begin{array}{l}50.1 \pm 14.7 \\
54.8 \pm 14.9 \\
56.9 \pm 11.4 \\
0.084\end{array}$ & $\begin{array}{l}45.5 \pm 15 . \\
47.3 \pm 15.1 \\
47.9 \pm 11.6 \\
0.742\end{array}$ & $\begin{array}{l}32.3 \pm 13.4 \\
44.7 \pm 12.9 \\
40.7 \pm 11.2 \\
0.008\end{array}$ & $\begin{array}{l}29.6 \pm 21.2 \\
38.6 \pm 10.4 \\
39.9 \pm 11.1 \\
0.002\end{array}$ & $\begin{array}{l}25.6 \pm 20.3 \\
37.3 \pm 21.7 \\
33.5 \pm 16.7 \\
<0.0001\end{array}$ \\
\hline
\end{tabular}

Abbreviations: OS, overall satisfaction; DTS, doctors' technical skills; DIE, doctors' information exchange; DAB, doctors' affective behavior; SNRT, overall satisfaction with nurses' \& radiology technologists' service; IHCT, interaction with health-care teams; OSTHOE, overall satisfaction with hospital organization and environment; AA, Addis Ababa; Gl, gastro-intestinal malignancies.

obtaining results of medical tests (mean score: 30 ), undergoing medical tests and/or treatments (mean score: 25 ) and the kindness and helpfulness of the technical, reception, and laboratory personnel (mean score: 35 ) were areas rated as poor. Conversely, these parameters were found to be better according to studies from China (73.05), ${ }^{20}$ Spain (69.2), ${ }^{19}$ and France (60.8). ${ }^{17}$ This difference might be due to high patient volume, shortage of medical resources, the long waiting time to get the service, difficulties with making an appointment and receiving medical treatment as a result of the availability of only one comprehensive center in Ethiopia and one cobalt 60 radiotherapy machine for a population of about 110 million.
Satisfaction in the care received from doctors, their availability and interpersonal skills, exchange of information, and their technical skills ranked relatively higher (50.2-52.6) compared to information provision, responsiveness, and affective behaviors of the nurses' and radiotherapy technologists (46.2). However, the satisfaction levels are still significantly lower than study reports from Australia (>90), ${ }^{11}$ Spain (70-95), ${ }^{19}$ and France (61.7-71.3). ${ }^{17}$ In addition, patients were more satisfied with doctors' affective behavior such as their ability to provide comfort and support, frequency of visits/consultations, and the time they devoted to treating them. On the other hand, they were less satisfied with the doctors' technical skills, such as awareness of the care 
and treatment received by the patient previously, attention to their physical symptoms, and information provision about the choice of treatment options and medical tests. This could be due to the high patient load in TASH with an inadequate number of oncologists in the center. This is the fact that there are only 6 adult oncologists at the country level. This is supported by the existing literature that patients wanted doctors to spend more time with them to properly treat and understand their degree of illness. ${ }^{21}$

Relatively better satisfaction (mean score: 46.4) was reported regarding the doctors' ability to give opportunity and involve the patients' family members in many aspects of treatment processes, compared with that for the hospital organization and premises (mean score: 33.7-35.5). But, still, this satisfaction level was lower than studies from Spain $(54.5 \%)^{19}$ and France $(59.3 \%$ in a local hospital and $61.9 \%$ in a teaching hospital). ${ }^{17}$

Among the seven domains of EORTC-PATSAT-33C, the patient's interaction with health-care team members ( $r=0.950$ ) was the most highly correlated subgroup/domain with overall patient satisfaction and ranked as number one, whereas correlation with doctors' information exchange was ranked as lowest $(r=0.632)$. This result was in disagreement with the Chinese study, in which doctors' information exchange and interpersonal skills were highly correlated to overall satisfaction compared to other domains. $^{20}$

Predictive factors for lower patient satisfaction were place of residence, gender, type of cancer, duration since treatment started, age, and source of health-care costs. These were significantly correlated with lower patient satisfaction, and place of residence accounted for the highest $(78.7 \%)$ value which is in line with similar studies done in European and Asian countries. ${ }^{7,17,22}$ The study participant being a resident of Addis Ababa where the treatment center is located (beta coefficient: 9.72) and health-care associated costs covered by the government (beta coefficient: 0.72 ) were positive predictors for better patient satisfaction which is in line with other studies. ${ }^{17,22}$ Economic-related issues were reported as independent predicting factors affecting patient satisfaction, where those living in Addis Ababa and treatment costs covered by the government incurred less cost compared to their counterparts. In addition, it might be due to better social life and support from their relatives or parents in the capital city. Increasing age (beta coefficient: 0.86) was also another positive predictive factor for patient satisfaction. This finding might be that older people place greater value on any care they receive when their own need of care is at its greatest.

Female study participants (beta coefficient: -3.66), patients treated from gynecological malignancy (beta coefficient: -2.33 ) and patients who were in the <6-month group since treatment started (beta coefficient: -0.91) were positively correlated for poor patient satisfaction. A possible explanation for this is that radiation treatment is a mainstay treatment option for patients treated for gynecological malignancy (cancer of the cervix is a common one in Ethiopia), ${ }^{23,24}$ a cancer only affecting females. Therefore, the availability of only one functional radiotherapy machine might be diligent with their disease conditions and long waiting time for the treatment that hugely affecting patients' satisfaction for the provided health-care services. This might also be a reason for the high treatment default rate in the center: among a cohort of 1149 patients, only $48.7 \%$ completed their treatment and only $25 \%$ of patients received adequate radiation therapy. $^{24}$

As a limitation, since self-reporting was used for the assessment of satisfaction, the present study was fully dependent on the patients' responses. In addition, the results may underestimate or overestimate patients' real satisfaction status. On the other hand, the quantitative nature of the data could not properly highlight the reasons for poor satisfaction from the patients' perspective. As this study was cross-sectional, fluctuations are likely to occur if the patient satisfaction using EORTC PATSAT-C33 is measured at multiple points in time and the predictors cannot establish causality between patient satisfaction and sociodemographic and clinical characteristics. Hence, future longitudinal studies are needed to observe fluctuations of patient satisfaction at a different point in time. In addition, the stage of cancer was not collected and controlled in the study which may have an impact on the level of patient satisfaction. Besides, the study had no control group to differentiate between the effects of all the independent variables on the satisfaction of patients treated for cancer. Despite all those limitations, this study provides preliminary evidence regarding the level of patient satisfaction at the oncology center of TASH. Additionally, identification of predictors could enable health-care providers working in the center, hospital, and the country in general to design appropriate intervention strategies to improve quality of care towards the provided services. Therefore, health-care providers should work collaboratively to improve patient 
Table 7 Factors Associated with Patient Satisfaction Among Those Patients Treated for Cancer at Tikur Anbessa Specialized Hospital, Coordination

\begin{tabular}{|c|c|c|c|c|c|c|c|c|c|}
\hline \multirow[t]{2}{*}{ Model } & \multirow[t]{2}{*}{$\begin{array}{l}\text { Predictor } \\
\text { Variables }\end{array}$} & \multirow[t]{2}{*}{$\begin{array}{l}\text { Adjusted } \\
\text { R Square }\end{array}$} & \multirow[t]{2}{*}{$\begin{array}{l}\text { R Square } \\
\text { Change }\end{array}$} & \multicolumn{2}{|l|}{$\begin{array}{l}\text { Change } \\
\text { Statistics }\end{array}$} & \multirow[t]{2}{*}{ p-value } & \multirow[t]{2}{*}{ Predictor Variable } & \multirow[t]{2}{*}{$\begin{array}{l}\text { Beta Coefficient } \\
(95 \% \mathrm{Cl})\end{array}$} & \multirow[t]{2}{*}{ S.E } \\
\hline & & & & F-Change & Df2 & & & & \\
\hline I & Residence & 0.787 & 0.787 & $|4| 4.947$ & 382 & $<0.0001$ & $\begin{array}{l}\text { Residence(ref: out of } \\
\text { AA) }\end{array}$ & $9.72(3.33,15.1)$ & 2.02 \\
\hline 2 & Sex & 0.819 & 0.032 & 67.73 & 381 & $<0.0001$ & Sex(ref: male) & $-3.66(-5.99,-|.4|)$ & 2.15 \\
\hline 3 & Type of cancer & 0.824 & 0.006 & 12.68 & 380 & $<0.0001$ & $\begin{array}{l}\text { Type of cancer(ref: } \\
\text { others) }\end{array}$ & & \\
\hline 4 & $\begin{array}{l}\text { Duration since } \\
\text { treatment } \\
\text { started }\end{array}$ & 0.827 & 0.003 & 6.778 & 379 & 0.01 & Gynecological & $-2.33(-6.31,-1.85)$ & 1.72 \\
\hline 5 & Age in years & 0.828 & 0.002 & 4.465 & 378 & 0.035 & Head and neck & $-1.19(-4.11,3.88)$ & 12.3 \\
\hline \multirow[t]{11}{*}{6} & $\begin{array}{l}\text { Sources of } \\
\text { health-care } \\
\text { costs }\end{array}$ & 0.830 & 0.002 & 4.514 & 377 & 0.034 & Breast & $1.05(-3.34,10.1)$ & 2.79 \\
\hline & & & & & & & GI & $-4.5 I(-12.1, \mid 4.3)$ & 8.21 \\
\hline & & & & & & & Sarcoma & $0.56(-5.9,8.31)$ & 11.21 \\
\hline & & & & & & & Lung & $-I .4 I(-8.66,5.1 I)$ & 4.32 \\
\hline & & & & & & & Lymphoma & $3.11(0.7 \mid 4,15.52)$ & 13.11 \\
\hline & & & & & & & Duration since & $-0.91(-6.11,-0.11)$ & 1.00 \\
\hline & & & & & & & treatment started(ref: & & \\
\hline & & & & & & & $\begin{array}{l}>6 \text { months since } \\
\text { treatment started) }\end{array}$ & & \\
\hline & & & & & & & Age in years & $0.86(0.2 I, 5.2 I)$ & 0.075 \\
\hline & & & & & & & Sources of health & $0.72(0.09,7.8 I)$ & 1.94 \\
\hline & & & & & & & care costs(ref: cash) & & \\
\hline
\end{tabular}

Abbreviations: SE, standard error, AA, Addis Ababa, GI, gastrointestinal, DF, degree of freedom, Cl, confidence interval.

satisfaction. Satisfied patients will adhere to their treatment and, subsequently, the treatment outcome will be improved.

\section{Conclusion}

In general, the mean overall level of satisfaction of patients treated at the outpatient adult oncology center of TASH was significantly lower than findings reported from studies in other countries. The finding is supported by a high treatment default rate in the center. Most patients died while they were waiting for their appointment. Hence, a concerted effort must be made to improve patient satisfaction in oncology health-care services in Ethiopia by expanding comprehensive cancer care services throughout the country and making necessary diagnostic and treatment modalities accessible and affordable for all.

\section{Data Sharing Statement}

The datasets used and/or analyzed during the current study are available from AMF on reasonable request.

\section{Ethics Approval and Consent Statement}

Ethical approval of the study and study protocol was obtained from AAU, CHS, school of pharmacy ethical review board (approval number: ERB/SOP/48/02/2019), and permission given by the adult oncology center of TASH. Permission to use the EORTC PATSAT-C33 tool was also obtained from EORTC quality of life group with an approval ID of 67536. The aims of the study were clearly explained to the study participants. Study information was collected from each participant after obtaining informed verbal consent which was approved by the ethics committee after clearly explaining the purpose and importance of the study. Individuals were informed that it is fully voluntary, they can withdraw from the study at any time or refuse to answer, can ask anything about the study and this would not affect the service they get from the health-care facilities. They were also informed that they would not receive any monetary incentive for participating in the study. For the purpose of confidentiality, participants' names were not used 
at the time of data collection; instead, a specific identification number was given to each participant. All other personal and health information was de-identified and kept separately, so every effort was made to maintain confidentiality throughout the study period and afterward.

\section{Acknowledgments}

The authors would like to thank all the study participants for their time and willingness to participate in the study. We would also like to forward our sincere gratitude to the outpatient adult oncology center of TASH and the data collectors for their support throughout the study period.

\section{Author Contributions}

AMF conceptualized the research, visualized and validated the study design, performed the statistical analysis; wrote, reviewed, and edited both the original draft and final manuscript; and handled all the editors' and reviewers' comments. DA participated in the conceptualization and visualization of the study design and statistical analysis; collection of the data and writing the original draft manuscript. All authors made substantial contributions to conception and design, acquisition of data, or analysis and interpretation of data; took part in drafting the article or revising it critically for important intellectual content; gave final approval of the version to be published; and agree to be accountable for all aspects of the work.

\section{Disclosure}

All the authors declare that they have no competing interests in this work.

\section{References}

1. Plummer M, de Martel C, Vignat J, Ferlay J, Bray F, Franceschi S. Global burden of cancers attributable to infections in 2012: a synthetic analysis. Lancet Glob Health. 2016;4(9):e609-16. doi:10.1016/S2214109X(16)30143-7

2. Heerdegen ACS, Petersen GS, Jervelund SS. Determinants of patient satisfaction with cancer care delivered by the Danish healthcare system. Cancer. 2017;123(15):2918-2926. doi:10.1002/cncr.30673

3. Abebe E, Abebe H. Types of cancers diagnosed and the preference of families of adult patients with cancer about disclosing diagnosis to the patients. Ethiop J Health Sci. 2017;27(3):255. doi:10.4314/ejhs.v2 $7 \mathrm{i} 3.7$

4. Williams B, Coyle J, Healy D. The meaning of patient satisfaction; an explanation of high reported values. Soc Sci Med. 1998;47:9. doi:10.1016/S0277-9536(98)00213-5

5. Backman C, Vanderloo S, Forster AJ. Measuring and improving quality in university hospitals in Canada: the collaborative for excellence in healthcare quality. Health Policy. 2016;120(9):982-986. doi:10.10 16/j.healthpol.2016.07.006
6. Merkouris A, Andreadou A, Athini E, et al. Assessment of patient satisfaction in public hospitals in Cyprus: a descriptive study. $J$ Health Sci. 2013;7(1):28-40.

7. Djambazov SN, Giammanco MD, Gitto L. Factors that predict overall patient satisfaction with oncology hospital care in Bulgaria. Value Heal Reg Issues. 2019;19:26-33. doi:10.1016/j.vhri.2018.11.006

8. Lis CG, Rodeghier M, Grutsch JF, Gupta D. Distribution and determinants of patient satisfaction in oncology with a focus on health related quality of life. BMC Health Serv Res. 2009. doi:10.1186/ 1472-6963-9-190

9. Sherlaw-Johnson C, Datta P, McCarthy M. Hospital differences in patient satisfaction with care for breast, colorectal, lung and prostate cancers. Eur J Cancer. 2008;44(11):1559-1565. doi:10.1016/j. ejca.2008.03.023

10. Kavadas V, Barham CP, Finch-Jones MD, et al. Assessment of satisfaction with care after inpatient treatment for oesophageal and gastric cancer. Br J Surg. 2004;91(6):719-723. doi:10.1002/bjs.4509

11. Philp S, Dalrymple C. Patient satisfaction with inpatient care provided by the Sydney Gynecological Oncology Group. Patient Relat Outcome Meas. 2010;179-184.

12. Tigeneh W, Molla A, Abreha A, Assefa M. Pattern of cancer in Tikur Anbessa specialized hospital oncology center in Ethiopia from 1998 to 2010. Int J Cancer Res Mol Mech. 1998;1.

13. Haileselassie W, Mulugeta T, Tigeneh W, Kaba M, Labisso WL. The situation of cancer treatment in Ethiopia: challenges and opportunities. J Cancer Prev. 2019;24(1):33-42. doi:10.15430/ JCP.2019.24.1.33

14. Brédart A, Anota A, Young T, et al. Phase III study of the European Organisation for Research and Treatment of Cancer satisfaction with cancer care core questionnaire (EORTC PATSAT-C33) and specific complementary outpatient module (EORTC OUT-PATSAT7). Eur $J$ Cancer Care (Engl). 2018;27(1):1-11.

15. Pourhoseingholi MA, Vahedi M, Rahimzadeh M. Sample size calculation in medical studies. Gastroenterol Hepatol Bed Bench. 2013;6 (1):14-17.

16. Sreenivas T, Babu NS. A STUDY ON PATIENT SATISFACTION IN HOSPITALS (A Study on Three Urban Hospitals in Guntur District, Andhra Pradesh). Int J Manag Research Bus Strateg. 2012;1.

17. Vân T, Nguyen F, Bosset J, et al. Determinants of patient satisfaction in ambulatory oncology: a cross sectional study based on the OUT-PATSAT35 questionnaire. BMC Cancer. 2011;11(1):526. doi:10.1186/1471-2407-11-526

18. Murakami G, Candidate ME, Mph YI. Patient perceived priorities between technical skills and interpersonal skills: their influence on correlates of patient satisfaction. J Eval Clin Pract. 2010;16 (3):560-568. doi:10.1111/j.1365-2753.2009.01160.x

19. Arraras JI, Rico M, Vila M, et al. The EORTC cancer outpatient satisfaction with care questionnaire in ambulatory radiotherapy: EORTC OUT-PATSAT35 RT. Validation study for Spanish patients. Psycooncology. 2010;19(6):657-664.

20. Zhang L, Dai Z, Cheng S, et al. Validation of EORTC IN-PATSAT32 for Chinese cancer patients. Support Care Cancer. 2015;23 (9):2721-2730. doi:10.1007/s00520-015-2636-6

21. Press D. Distribution and determinants of patient satisfaction in oncology: A review of the literature. Patient Prefer Adherence. 2009;287-304.

22. Coens C, Aaronson N, Chie W, et al. Determinants of patient satisfaction in oncology settings from European and Asian countries: preliminary results based on the EORTC IN-PATSAT32 questionnaire. Eur J Cancer. 2007;43(2):323-330. doi:10.1016/j.ejca.2006.10.016

23. Tigeneh W, Aberha MA, Mathiwos A. Pattern of cancer in Tikur Anbessa specialized hospital oncology Center in Ethiopia from 1998 to 2010. Int J Cancer Res Mol Mech. 2015;1:1. doi:10.16966/2381-3318.103

24. Feuchtner J, Mathewos A, Solomon A, et al. Addis Ababa population-based pattern of cancer therapy, Ethiopia. PLoS One. 2019;14(9):e0219519. doi:10.1371/journal.pone.0219519 


\section{Publish your work in this journal}

Patient Preference and Adherence is an international, peer-reviewed, open access journal that focuses on the growing importance of patient preference and adherence throughout the therapeutic continuum. Patient satisfaction, acceptability, quality of life, compliance, persistence and their role in developing new therapeutic modalities and compounds to optimize clinical outcomes for existing disease

Submit your manuscript here: https://www.dovepress.com/patient-preference-and-adherence-journa states are major areas of interest for the journal. This journal has been accepted for indexing on PubMed Central. The manuscript management system is completely online and includes a very quick and fair peer-review system, which is all easy to use. Visit http:// www.dovepress.com/testimonials.php to read real quotes from published authors. 